\title{
La ética, naturalmente derivada de \\ la ontología en Tomás de Aquino
}

Ethic, naturally derived from ontology in Thomas Aquinas

\author{
AUGUSTO TRUJILLO WERNER \\ Universidad de Málaga
}

recibido: 01.03.2016

aceptado: 27.07.2016

\section{RESUMEN}

Este artículo académico trata sobre cómo Aquino entendía: a) la aprehensión de las primeras nociones intelectas universales: ens, verum et bonum simpliciter; b) la fructificación de los primeros preceptos y de los segundos preceptos prácticos en la persona genuinamente humana o racional; c) la ética, ley moral natural, como esencialmente derivada de la ontología. Ens compuesto de naturaleza humana, entendida metafísicamente y acto del ser, ordenado al bonum; d) por tanto, la ley natural solo tiene sentido desde una visión metafísica, no meramente física o material.

\section{PALABRAS CLAVES \\ AQUINO, ONTOLOGÍA, ÉTICA, RAZÓN PRÁCTICA, LEY NATURAL}

\section{ABSTRACT}

This scholarship article explains how Aquinas understood: a) apprehension of the first intellectual concepts: ens, verum et bonum simpliciter; b) establishment of the first and the second practical commandments in a person, genuinely human or rational; c) ethic, natural law, as essentially derived from ontology. Ens compound of human nature, understood metaphysically, and act of being, ordered to bonum; d) therefore, natural law only makes sense from a metaphysical sight, not a merely physical or material view.

KEY WORDS

AQUINAS, ONTOLOGY, ETHICS, PRACTICAL REASON, NATURAL LAW

Claridades. Revista de filosofía 8 (2016), pp. 49-65

ISSN: 1889-6855 ISSN-e: 1989-3787 Dl.: PM 1131-2009

Asociación para la promoción de la Filosofía y la Cultura (FICUM) 


\section{INTRODUCCIÓN}

Mi tesis quiere demostrar que la ética (sobre todo ley moral natural) de Tomás de Aquino es una consecuencia natural de su ontología (sobre todo naturaleza humana y acto del ser). Para ello:

$1^{\circ}$. Se considerará la aprehensión intelectual de los conceptos universales y simpliciter de ens, verum y bonum, y el concepto de ente compuesto de (esencia o) naturaleza humana y acto de ser.

$2^{\circ}$. Se estudiará la fructificación de los primeros juicios de la razón práctica, y la diferencia entre los primeros y segundos preceptos de la ley moral natural, "Lex naturalis est aliquid per rationem constitutum". Asimismo se diferenciará entre las tendencias humanas universales o humanas in quanto talis, (que son la materia de los preceptos de la ley moral natural) y las tendencias particulares de cada persona (que no pueden ser la materia de la ley moral natural, pues esta es universal). Concluyendo que el concepto tomista de naturaleza bumana y de ley natural solo puede ser concebido en sentido metafísico, no confundiendo la ley moral natural con las inclinaciones de una persona particular.

$3^{\circ}$. Se comprobará cómo demostrando lo anterior se conviene en que de hecho la ética tomista es fruto de su ontología y la relación íntima entre estos elementos desde la ontología hasta la ética: ens, bonum, naturaleza humana, razón práctica y ley natural.

\section{ENS, VERUM ET BONUM SIMPLICITER}

Ante todo en sus textos se afirma, aunque el Aquinate no entra en detalles de edad, cómo solo a partir de cierto periodo, ${ }^{2}$ semanas o meses de vida, ${ }^{3}$ se puede hablar de aprehensión intelectual del ente en cuanto tal, de la verdad universal y del bien ontológico en el ente verdadero y bueno singular. ${ }^{4}$ Se puede sostener que en la filosofía del Aquinate ${ }^{5}$ las primeras

\footnotetext{
${ }^{1}$ S. Th., I-II, q. 94, a.1, co.

${ }^{2}$ La edad del uso de la razón no es homogénea entre los psicólogos evolutivos. Véase, AA.VV http://www.urbanchildinstitute.org/why-0-3/baby-and-brain.

${ }^{3}$ En este paper se ejemplifica sobre todo con un niño (o niña) pequeño, pues resulta más claro y evidente cómo hay un periodo en que claramente no posee uso de razón y después se puede afirmar objetivamente que la misma persona pasó de no tener uso de razón a poseerla.

${ }^{4}$ Cfr, De veritate, q. 2 a. 3 ad 19.

${ }^{5}$ Cfr. en particular el amplio tratado sobre la persona en S. Th., I, qq. 75-89.
}

Claridades. Revista de filosofía 8 (2016) 
nociones universales y simpliciter: ens, verum, bonum -también se llaman semillas sapienciales ${ }^{6}$-, solo se abstraen y explicitan después de un cierto tiempo de vida, dado que tanto en el bebé de pocas semanas (por un insuficiente desarrollo cerebral ${ }^{7}$ ), como en el adulto que sufre una severísima carencia cerebral, se impide que las potencias sensitivas internas sentido común, imaginativa, memoria y cogitativa- funcionen correctamente y produzcan la especie sensible.

El uso de la razón depende en cierto modo de las potencias sensitivas. Si el sentido está impedido, e impedidas también las potencias sensitivas internas, el hombre no tiene perfecto uso de razón. Es el caso de los que duermen o de los locos. Las potencias sensitivas son orgánicas. Por eso, los actos y también el uso de la razón quedan impedidos si los órganos están imposibilitados. En los niños (...) no se da el perfecto uso de razón, como tampoco de los demás miembros (corporales: brazos, piernas, etc.). ${ }^{8}$

Las potencias sensitivas internas son orgánicas, teniendo su sede en el cerebro, siendo necesarias para la racionalidad ${ }^{9}$-aunque la inteligencia y la voluntad son potencias inorgánicas e inmateriales-, dado que el intelecto agente necesita de la especie sensible sobre la que actúa iluminando y produciendo la especie inteligible. Esta especie inteligible es recibida por el intelecto en potencia, que es el que finalmente produce la especie intelecta expresa, concepto o noción universal.

Es imposible que nuestro entendimiento (...), que se encuentra unido a un cuerpo pasible, entienda en acto algo sin recurrir a las imágenes. (...), porque al ser el entendimiento una facultad que no se sirve de ningún órgano corporal, de ninguna manera estaría impedido su acto por la lesión de un órgano corporal si para su ejercicio no necesitase el acto de otra facultad que sí utiliza dichos órganos. Las potencias que sirven de órganos corporales son el sentido, la imaginación y las otras facultades de la parte sensitiva. Por eso resulta evidente que para que el entendimiento entienda en acto, y no sólo cuando por primera vez adquiera un conocimiento, sino también en la posterior utilización del conocimiento adquirido, se precisa el acto de la imaginación y el de las demás facultades. Pues observamos que, impedido el acto de la imaginación por la lesión

${ }^{6}$ Cfr., S. Th., I-II, q. 63, a. 1, co.

${ }^{7}$ Cfr., Abbot, http://www.nature.com/news/neuroscience-the-brain-interrupted-

1.16831. Falta de desarrollo cerebral.

${ }^{8}$ S. Th., I, q. 101, a. 2, co. Cursiva y paréntesis míos.

${ }_{9}$ Cfr., S. Th., I, q. 101, a. 2, ad 1. 
de un órgano, como sucede en los dementes, o impedida la facultad de la memoria, como sucede en los que se encuentran en estado de letargo, el hombre no puede entender en acto ni siquiera aquellas cosas cuyo conocimiento ya había adquirido. ${ }^{10}$

En este sentido añade que "el intelecto humano, al inicio, es similar a una tablilla sobre la cual no hay escrito nada, pero a continuación se acumula la ciencia mediante los sentidos y en virtud del intelecto agente". ${ }^{11}$ I.e., la falta de desarrollo cerebral hace que éste se encuentre en las primeras semanas como obnubilado e inoperante en acto; si bien los sentidos externos pueden ser estimulados correctamente por las sensaciones externas. V.g., el bebé mueve la cabeza hacia un sonido que le llama la atención, o sigue correctamente con los ojos la pelota dorada que el médico le muestra para analizar su grado de visión. Mas, los sentidos internos, por causa del mal funcionamiento de su órgano, no están en condiciones de suministrar la especie sensible al intelecto agente, por tanto éste no puede presentar nada al intelecto posible, el cual consecuentemente no expresa ninguna noción universal o simpliciter.

(Dado que) en los niños el humor linfático ${ }^{12}$ debe necesariamente abundar en el cerebro. En el cual tienen el propio órgano la potencia imaginativa, estimativa (cogitativa en el ser humano), memorativa y el sentido común, debían necesariamente ser obstaculizados sobre todo los actos de estas facultades y, por consecuencia, también el intelecto, el cual recibe inmediatamente el conocimiento de tales potencias y a esas se refiere cada vez que es en acto. ${ }^{13}$

Resulta claro, pues, que para el Aquinate, durante las primeras semanas de vida, el cerebro todavía no está suficientemente desarrollado para elaborar y presentar una especie sensible al intelecto agente. Continuando el argumento, nuestro autor diferencia claramente entre la aprehensión intelectual de las primerísimas nociones universales de ens, verum,

\footnotetext{
${ }^{10}$ S. Th., I, q. 84, a. 7, co. A fortiori, más se dará con respecto a los bebés que nunca habían poseído nociones universales.

${ }^{11}$ De Veritate, q. 18, a. 7, co. Esta doctrina se debe entender de modo genuinamente tomístico. El intelecto humano es una tablilla donde todavía no hay nada escrito, entendido en acto, pero sí que posee el intelecto y la voluntad en potencia y todas las capacidades para entender ideas intelectas en acto.

12 Aquino siguiendo la medicina hasta el s. XIV en vez de falta de desarrollo cerebral él se refiere "al exceso de humedad"; pero la esencia sigue siendo la misma: los bebés de un mes no entienden en acto.

${ }^{13}$ De Veritate, q. 18, a. 8, co.
}

Claridades. Revista de filosofía 8 (2016) 
bonum y el mero sentir de una persona que, por causa del mal funcionamiento del cerebro, -llámese bebé, o persona que llegó a adulto con gravísimas deficiencias cerebrales- posee sentidos internos pero aún no están capacitados para ofrecer ninguna especie sensible al intelecto agente.

Si pues, el niño es inteligente en potencia, aunque actualmente no entienda, deberá haber en él alguna potencia mediante la cual sea capaz de entender. Y esta potencia es el entendimiento posible. Luego el entendimiento posible deberá estar unido al niño antes de que éste entienda en acto (...). (Por tanto, hubo un tiempo en que no entendió en acto, sino que entendería en potencia) El niño es inteligente en potencia, no como si todavía no tuviese la naturaleza para entender, sino como teniendo impedimento para que entienda, porque está impedido para entender (...) por eso, quitado el impedimento, inmediatamente entiende. ${ }^{14}$

No entiende en acto, porque el intelecto posible todavía no ha recibido ninguna especie inteligible del intelecto agente. Ciertamente estas personas son capaces de reacciones, pero se debe remarcar que son reacciones solo sensitivas, dado que no llegan a ser reacciones intelectivas ni son movidas por la voluntad. ${ }^{15}$

Se debe señalar que el objeto del intelecto o razón es la naturaleza, esencia o quidditas del ente. El modo de conocer la naturaleza de los entes, propio del hombre o persona, es a través de los sentidos, de los accidentes, como si fueran puertas. Por esto se llama razón, pues es un conocimiento discursivo. ${ }^{16}$ Además la operación del intelecto o razón es doble. Una es la aprehensión de la naturaleza o esencia de un ente. Otra es la operación o juicio de los primeros principios del intelecto o razón, práctico o teórico; componiendo (afirmando) o dividiendo (negando) una sentencia o afirmación, práctica o teórica. ${ }^{17} \mathrm{El}$ entendimiento práctico como el teórico poseen como objeto la verdad, pero en la razón teórica se trata de la verdad en sí, mientras que en la razón práctica se trata de la verdad ordenada a la operación; siendo la verdad justa la regla y gobernante de la acción humana, o sea, racional. ${ }^{18}$

\footnotetext{
${ }^{14}$ Contra Gentiles, lib. 2 cap. 60. Cursiva y paréntesis míos.

${ }^{15}$ Cfr., De Veritate, q. 18, a. 8, ad. 2.

${ }^{16}$ Cfr., Super Sent., lib. 3 d. 35 q. 2 a. 2 qc. 1 co.

${ }^{17}$ Cfr., Expositio Peryermeneias, pr. 1.

18 Cfr., SELLÉS, F., Razón teórica y razón práctica según Tomás de Aquino, Anuario filosófico 101 (1991), 1-87, p. 26.
} 
El concepto de naturaleza en Aquino tiene sin duda raíces aristotélicas, y el Filósofo tanto usaba el concepto naturaleza en los libros de Física como de Metafísica. Desde entonces existe un uso legítimo del término naturaleza tanto en el campo de las ciencias empíricas como metafísicas. Por tanto se puede afirmar que el concepto naturaleza es analógico, esto quiere decir que en cada caso el término naturaleza se aplica distintamente. El hombre posee una naturaleza, el animal posee una naturale$z a$, la planta posee una naturaleza y la piedra que cae al suelo posee una naturaleza. O sea, sería altamente erróneo, y Aquino lo tiene muy claro, meter a todos estos entes en el mismo saco, y poner la etiqueta de naturaleza a todos. Además, la doctrina natural significa que todos los seres poseen en sí mismos el principio de actuación, lo que implica autonomía. I.e., todas las sustancias por sus respectivas naturalezas poseen tendencias intrínsecas hacia sus propios fines según la ley eterna que es el pensamiento ordenador de Dios; recuérdese que la ley natural es una participación de la ley eterna en la persona. Por lo tanto, la naturaleza añade a la esencia su aspecto de movimiento, y principio de acción; lo que supone que el concepto de appetitus, como el de naturaleza, es necesariamente también un concepto analógico. La naturaleza de cada sustancia tiende hacia su fin y el appetitus dependerá de la naturaleza específica de cada ente. Por tanto, sería igualmente un gravísimo error coger a todos los entes racionales -con apetito intelectual o voluntad- e irracionales -sin voluntad intelectual-, y meterlos en un saco común con la etiqueta de appetitus. $^{19}$

\section{LA FRUCTIFICACIÓN DE LOS PRECEPTOS DE LA LEY MORAL NATURAL}

A la luz de esta doctrina se puede afirmar que la ley moral natural presupone un conocimiento de la naturaleza en general y de la naturaleza humana en particular. ${ }^{20} \mathrm{La}$ enunciación de los preceptos prácticos de la ley moral natural será derivada de los primeros conceptos universales, ontológicos y simpliciter. La razón practica solo los fructificará naturalmente como imperativo moral ordenados a la acción real -tanto universal: " haz.

\footnotetext{
${ }^{19}$ Cfr., COTTIER, G.M., "Proposiçoes acerca do conceito de naturaleza humana sobre o direito natural”, Aquinate 12 (2010), 12-16; S. Th., I-II, q. 94, a. 2, co.

${ }^{20}$ Cfr., DEWAN, L., 'St. Tomás, our natural lights, and the moral order", Angelicum 67 (1986), 283-307, pp. 298-302.
}

Claridades. Revista de filosofía 8 (2016) 
el bien (general) y evita el mal (general)", como particular: "baz el bien (humano) y evita el mal (humano)- cuando el intelecto y la voluntad ya conozcan y quieran (o no quieran y eviten) en acto las nociones universales de ente-no ente, verdadero-falso, bueno-malo y las nociones concretas de bien y mal para el hombre; lo que implica conocer y querer la noción de naturaleza humana y las inclinaciones humanas en cuanto tales. O sea, la ley moral natural es también fruto de la experiencia moral. "La comprensión de los principios (puede ser) imperfectísima (pero) nace de nuestra propia naturaleza, y no del estudio humano acerca de la verdad." 22 La razón se sirve de las tendencias naturales humanas en cuanto tales -o sea tendencias gobernadas y resultado de la inteligencia y la vo$\operatorname{luntad}^{23}$ - a modo de indicador, señalando a la razón práctica y a la voluntad sobre qué parte de la naturaleza humana deben fijarse para fructificar el precepto de la ley moral natural: ${ }^{24}$ y "es natural, por radicar en los principios de la naturaleza humana". ${ }^{25}$

Usando la analogía entre el orden de las verdades teóricas y prácticas Aquino determina el funcionamiento de la ley moral natural como racional, como ordo preceptorum, pues ordo implica necesariamente racionalidad. ${ }^{26}$ Por esto la ley moral natural es el conjunto de los primeros preceptos queridos por la voluntad y aprehendidos por la razón práctica de toda persona (con uso de razón) y el conjunto de los preceptos secundarios derivados necesaria e inmediatamente de los primeros preceptos, aprehendidos y queridos naturalmente por las personas. ${ }^{27}$ A continuación se presenta cómo el Aquinate relacionaba las tendencias universales de todos los hombres con los primeros principios de la ley natural.

"Todo agente obra por un fin, y el fin tiene razón de bien. De abi que el primer principio de la razón práctica es el que se funda sobre la noción de bien, y se formula asi: «el bien es lo que todos apetecen». En consecuencia, el primer precepto de la ley es éste: «El bien ha de hacerse $y$

\footnotetext{
${ }^{21}$ Cfr., GARCÍA, J., Metafísica tomista. Ontología, gnoseología y teología natural, Pamplona, EUNSA, 2001, pp. 424-427.

${ }^{22}$ Contra Gentiles, lib. 3 cap. 37. Paréntesis míos.

${ }^{23}$ Cfr., BROCK, S.L., The legal character of natural law according to St. Thomas Aquinas, University of Toronto, Toronto, 1988, pp. 158-159; S. Th., I-II, q. 94, a. 4, co.

${ }^{24}$ Cfr., S. Th., I-II, q. 89, a 6, co.

25 S. Th., I, q. 99, a. 1. co.

${ }^{26}$ Cfr., HENLE, R, The Treatise on Law, University of Notre Dame press, Indiana, 1993 , pp. 247-248.

${ }_{27}$ Cfr., Suma de Teología. Parte I-II, p. 732
}

Claridades. Revista de filosofía 8 (2016) 
buscarse; el mal ha de evitarse». Y sobre éste se fundan todos los demás preceptos de la ley natural (...). Encontramos (...) en el hombre una inclinación que le es común con todas las sustancias, consistente en que toda sustancia tiende por naturaleza a conservar su propio ser. Y de acuerdo con esta inclinación pertenece a la ley natural todo aquello que ayuda a la conservación de la vida humana (...). Encontramos en el hombre una inclinación (...) según la naturaleza que tiene en común con los demás animales. $\mathrm{Y}$ a tenor de esta inclinación se consideran de ley natural las cosas que la naturaleza ha enseñado a todos los animales, tales como la conjunción de los sexos, la educación de los hijos y otras cosas semejantes (...). Hay en el hombre una inclinación al bien correspondiente a la naturaleza racional, que es la suya propia, como es, por ejemplo, la inclinación natural a buscar la verdad acerca de Dios y a vivir en sociedad. Y, según esto, pertenece a la ley natural todo lo que atañe a esta inclinación, como evitar la ignorancia, evitar ofender con quien uno debe vivir y todo lo demás relacionado con esto." 28

En este locus Aquino trata exclusivamente sobre el ser humano en cuanto tal, o sea, en cuanto racional, y de las inclinaciones humanas en cuanto tal, i.e., dominadas, regidas o gobernadas por la razón, "la razón domina y manda sobre (...) las inclinaciones naturales, (por tanto) las inclinaciones humanas deben ser regidas por la razón" ${ }^{29}$ Esto supone que la inclinación humana se refiere al hombre en cuanto humano, i.e., lo genuina y específicamente humano, no la concepción e inclinación que pueda tener sobre la vida ajena un asesino en serie con "la razón oscurecida por una pasión, por una mala costumbre o por una torcida disposición natural." 30 O la concepción y tendencia que pueda tener un cleptómano sobre y hacia la propiedad privada. En el Corpus Thomisticum ante todo un hombre completamente libre, ya que quien quiere la cosa o la acción mala (matar, violar, cometer adulterio, etc.,) no es íntegramente libre, ${ }^{31}$ es el hombre en cuanto humano o en cuanto tal. Con esta expresión hombre en cuanto bumano o en cuanto tal o simplemente persona se hace referencia a lo propio, genuino y exclusivo de la especie humana: actuar conforme a la inteligencia y a la voluntad, por tanto, conforme a la naturaleza humana. Pero también actuar conforme a las tendencias genuinamente humanas: no matar, no violar, no robar. ${ }^{32}$ Las acciones humanas son solo las del

\footnotetext{
${ }^{28}$ S. Th., I-II, q. 94, a. 2, co. Cursiva mía.

${ }^{29}$ S. Th., I-II, q. 94, a. 4, ad 3.

${ }^{30}$ S. Th., I-II, q. 94, a. 4, co.

${ }^{31}$ Mas bien está cegado y es, en cierto sentido, esclavo de sus pasiones. Cfr., De veritate, q. 22 , a. 6, co.

${ }^{32}$ Cfr., S. Th., I -II q.71 a.2, co.
}

Claridades. Revista de filosofía 8 (2016) 
hombre en cuanto persona racional, i.e., dueño de sus actos. Las demás acciones pueden llamarse del hombre pero no humanas en cuanto tales, porque no son del hombre en cuanto es hombre. "Sed non proprie humanae, cum non sint hominis inquantum est homo." ${ }^{, 33} \mathrm{El}$ objeto de la voluntad es el fin y el bien, por lo que todas las acciones humanas son por un fin racional. $^{34}$

Dios actúa en cada cosa en conformidad con las condiciones de cada una; así en las cosas naturales (animales, como un delfín o un perro, plantas y minerales) interviene suministrándoles el poder de actuar determinado de sus respectivas naturalezas (...). Sin embargo (en los seres bumanos) con libre arbitrio interviene dándoles el poder de actuar libremente (bien o mal). ${ }^{35}$

En este sentido, las inclinaciones naturales propias de un individuo son aquellas que surgen de su naturaleza humana. Las inclinaciones del ser humano surgen de su naturaleza racional, la cual es la forma genuina y específicamente humana. Las inclinaciones que son naturales, de acuerdo a la naturaleza de la especie hombre, son aquellas que brotan de la naturaleza racional, la cual es la forma por la que una persona se puede situar en su especie humana y estas tendencias sí pertenecen a la ley moral natural, ${ }^{36}$ como se afirma en este texto: "Pertenece a la ley natural todo aquello a lo cual el hombre se encuentra naturalmente inclinado, dentro de lo cual lo especifico del hombre es que se sienta inclinado a obrar conforme a la razón." 37

Esto no quiere decir que una persona por actuar voluntariamente de forma ilícita o no ética deja por ello de ser persona, libre u hombre en cuanto tal, "la voluntad es libre porque no está sujeta a ninguna necesidad (de cualquier bien finito, y por tanto) (...) en relación al fin (finito) puede querer el bien o el mal. ${ }^{\text {,3 }}$ Sin embargo, sí se puede sostener con Aquino, que en ese acto o tendencia, esa persona particular no está siguiendo lo específicamente natural humano en cuanto tal, y en este sentido, se está autodespersonificando un poco, y se está autodesliberando un poco. "Cualquier voluntad creada puede empeorar en su acto porque proviene

\footnotetext{
${ }^{33}$ S. Th., I-II, q. 1, a.1, co.

${ }^{34}$ Cfr. S. Th., I-II, q. 1, a. 1, co.

35 Super Sent., lib. 2 d. 25 q. 1 a. 1, ad 3. Cursiva y paréntesis míos.

${ }^{36}$ Cfr., The legal character of natural law... op. cit., pp. 158-159.

${ }^{37}$ S. Th. I-II, q. 94, a. 4, co. Cursiva mía.

${ }_{38}$ De veritate, q. 22, a.6, co.
} 
de la nada y puede por tanto deteriorarse." 39 Tampoco quiere decir que cualquier tendencia de cualquier persona fruto o gobernada por la razón práctica, por más buena que sea, v.g., sentirse atraído a curar las heridas de los enfermos, pertenezca a la ley moral natural. Puesto que hay personas libres y racionales que no se sienten naturalmente inclinados a curar las heridas de los enfermos. Tampoco quiere decir que un asesino, un ladrón o un violador busquen su mal. Para Aquino todas las personas actúan buscando algún bien, aunque a veces este bien sea un mal disfrazado de bien. ${ }^{40} \mathrm{El}$ asesino busca su bien, satisfacer su ira; el ladrón busca su bien, satisfacer su avaricia; el violador busca su bien, satisfacer su apetito sexual, etc. Resumiendo, para que una tendencia pertenezca a la ley moral natural debe cumplir estos dos requisitos: estar gobernada y ser resultado de la razón práctica y que cualquier persona tienda a ese bien naturalmente.

En este sentido para nuestro autor la ley, en este caso la ley moral natural, se define como "una ordenación de la razón al bien común" Consecuentemente lo esencial de la ley moral natural es que sea fruto de la razón práctica ordenada al bien (ontológico, no al bien egoísta y subjetivo de una persona particular). Esto significa que sin ordenación al bien simpliciter, ontológico o con propiedad trascendental, no hay ley propia ni esencialmente. ${ }^{42}$

Por tanto, una definición errada de ley moral natural sería especificarla como un simple instinto natural del hombre. La verdadera y justa definición de ley natural solo es fruto de la razón humana como precepto de la inteligencia de cualquier persona hacia su fin. Por esto es injusto y falso afirmar que Tomás de Aquino confundía la ley moral natural con las inclinaciones de cualquier hombre. Al contrario, él mantenía que la ley natural era fruto de la razón práctica de cualquier hombre, ordenando las acciones e inclinaciones teleológicamente al fin humano. Aunque esta dictamina sobre las inclinaciones humanas, como su materia altamente contingente. Esta es la esencia ética de la persona. ${ }^{43}$ Pues para Aquino "la ley (moral) natural no es otra cosa que la participación de la ley eterna en

39 Super sententiae, d. 39, q. 1, a.1, co.

${ }^{40}$ Cfr., S. Th., I, q. 48, a. 3, co.

${ }^{41}$ S. Th., I-II q. 90, a. 4, co.

${ }^{42}$ Cfr., Suma de Teología. Parte I-II, p. 123

${ }^{43}$ Cfr., Suma de Teología. Parte I-II, pp. 710-711

Claridades. Revista de filosofía 8 (2016) 
la criatura racional." 44 Y la ley eterna es el mismo intelecto y voluntad Divina que considera toda la creación ordenada, actuando y persiguiendo sus fines propios, en orden al bien común universal; algunos seres racional y libremente, como el hombre, y otros irracionalmente. ${ }^{45}$

Respecto a los preceptos secundarios de la ley natural v.g., no robar, no matar o devolver el depósito (prestado), son conclusiones particulares (y necesarias) de la razón práctica ${ }^{46}$ derivadas de los cuatro primeros preceptos. Estos preceptos secundarios son rectos en la mayoría de los casos, pero fallan algunas veces. ${ }^{47}$

Se debe concluir que la ley natural, en cuanto a los primeros principios universales, es la misma para todos los hombres, tanto en el contenido (voluntad, querer) como en el grado de conocimiento (aprehensión). Mas en cuanto a ciertos preceptos particulares, que son como conclusiones derivadas de los principios universales, también es la misma bajo ambos aspectos en la mayor parte de los casos; pero pueden ocurrir algunas excepciones, ya sea en cuanto a la rectitud del contenido (voluntad, querer), a causa de algún impedimento especial (...); ya sea en cuanto al grado del conocimiento (aprehensión), debido a que algunos tienen la razón oscurecida por una pasión, por una mala costumbre o por una torcida disposición natural. Y así (...) entre los germanos no se consideraba ilícito el robo a pesar de que es expresamente contrario a la ley natural (un precepto segundo de la ley moral natural, no primero). ${ }^{48}$

Hay un límite moral natural, que ninguna persona puede transgredir. Como máximo los errores de comprensión y de volición, serán relativos a los preceptos segundos de la ley moral natural; nunca respecto a los primeros preceptos de la ley moral natural. Frente a estos primeros ni el intelecto puede engañarse o ser engañado, ni la voluntad quererlos por mucha presión que hagan los apetitos inferiores. ${ }^{49}$ Aunque la voluntad sea una potencia inmaterial y por tanto espiritual; estos quereres ilícitos se dan porque la voluntad accede a lo que las pasiones de la misma persona le ofrecen, y ésta, la voluntad, consigue que el intelecto se fije en los

\footnotetext{
44 S. Th., I-II, q. 91, a.2, co.

${ }^{45}$ Cfr., Suma de Teología. Parte I-II, p. 80

${ }^{46}$ S. Th., I-II, q. 94, a.4, co.

${ }^{47}$ S. Th., I-II, q. 94, a.4, ad 2

${ }^{48} \mathrm{~S}$. Th., I-II, q. 94, a. 4, co. Paréntesis y cursiva míos.

${ }^{49}$ Cfr., De malo, q. 7, a. 6, co
} 
aspectos buenos que esa acción ilícita, como robar o cometer adulterio, pueda tener. ${ }^{50}$

"Aquello que causa el movimiento como un bien desiderable difiere de aquel que causa el movimiento como un bien inteligible (...). Esto es particularmente evidente en el caso de una persona incontinente. Porque de acuerdo a su razón ésta se mueve por un bien inteligible, pero de acuerdo a su potencia concupiscible ésta se mueve por algo atrayente a los sentidos, lo cual aunque parece ser bueno, no es bueno absolutamente sino solo secundum quid (...). La razón es que un bien concupiscible, que no es un bien inteligible, es meramente un bien aparente. Pero el primer bien debe ser objeto de la voluntad i.e., un objeto deseado por el apetito intelectual. Porque la voluntad pertenece al orden intelectual y no meramente al apetito concupiscible. Y esto es así porque lo que es deseado por la potencia concupiscible parece ser bueno porque es deseado. Porque la concupiscencia pervierte el juicio de la razón (el apetito sensible siempre viene después del juicio racional práctico) y se ve como bueno lo que es (simplemente) agradable (a la sensualitas). Pero lo que es deseado por el apetito intelectual es deseado porque es bueno secundum se (...). De este modo el apetito concupiscible (...) es bueno solo cuando es deseado a través de un dictado de la razón. ${ }^{\prime 51}$

$\mathrm{Al}$ respecto de la sindéresis, se debe señalar con el Aquinate que es el hábito natural cuasi innato que, en cuanto hábito, recuerda a la razón, en el sentido de dar un conocimiento inmediato, los preceptos de la ley moral natural ${ }^{52}$ que son los principios del conocimiento práctico. ${ }^{53} \mathrm{La}$ conciencia es el acto de la razón práctica, la ley moral natural es más bien el fruto de la razón práctica, y el hábito de los primeros principios de la ley moral natural es la sindéresis. Ésta dictamina universalmente los preceptos de la ley moral natural, mientras que la conciencia establece lo que se debe realizar u omitir en cada caso práctico particular. Por tanto, la sindéresis no puede errar, ya que no puede ser aturdida, enajenada o confundida por ninguna pasión, ${ }^{54}$ mas la conciencia al aplicar la norma o principio general al caso o conclusión particular sí. ${ }^{55} \mathrm{La}$ sindéresis conoce los primeros principios de la ley moral natural cuando el intelecto fructifica los primeros principios de la ley moral natural. I.e., antes va la potencia que su hábito. La sindéresis guarda y recuerda los primeros principios de la ley moral natural al intelecto práctico cuando éste va a buscarlos. "La sin-

\footnotetext{
${ }^{50}$ Cfr., De malo, q. 4, a. 1, co.

51 Sententia Metaphysicae, lib. 12 1. 7. Cursiva y paréntesis míos.

${ }^{52}$ Cfr., De veritate, q. 16, a. 2, co.

${ }^{53}$ Cfr., De veritate, q. 16 , a. 1 , co.

${ }^{54}$ Cfr., Super sent., lib. 2, d. 39, q. 3, a. 1, ad 1.

55 Cfr., ROYO, A., Teología moral para seglares, v.I, La BAC, Madrid, 2012,pp. 129-131.
}

Claridades. Revista de filosofía 8 (2016) 
déresis es (...) un hábito que contiene los preceptos de la ley natural que son principios primeros del obrar humano. ${ }^{, 56}$

Se debe sostener que la ley moral natural nos resulta tan oscura, enredada y complicada, pero a la vez tan atractiva, interesante y atrayente, porque la razón práctica más que participar en la intelección con que Dios conoce la ley eterna -de la que la ley moral natural es una participación en el ser humano- participa de la voluntad Divina respecto a ella, por esto es muy complicado comprenderla pero muy fácil quererla. ${ }^{57} \mathrm{Se}$ puede sustentar análogamente, que si la sindéresis es el hábito del intelecto práctico, así también la inteligencia es el hábito del intelecto especulativo cuando aprendemos algo. ${ }^{58}$ I.e., una norma aritmética o una norma moral la podemos conservar aunque pensemos solo puntualmente en esta. $^{59}$

\section{LA ÉTICA HUMANA (LEY NATURAL) DERIVADA NATURALMENTE DES- DE LA ONTOLOGÍA PERSONAL (ENS COMPUESTO DE ACTO DE SER Y NA- TURALEZA HUMANA ORDENADA AL BONUM) EN AQUINO}

Lo bueno coincide con el ente, si bien la noción de bueno añade al ente una relación con el apetito. Lo bueno, formalmente se refiere a las operaciones buenas según la naturaleza del ente real al que siempre está necesariamente unido. El ens que supone un bonum (perfección humana) no es solo la naturaleza humana, ni es solo el acto de ser, ni las solas operaciones, sino que el ens que produce un bonum es, sobre todo, una necesidad de la razón práctica que al conocerse y conocer otros seres produce naturalmente los primeros juicios prácticos de la ley moral natural, que es una participación de la ley eterna en la criatura racional. Por tanto, es un conocer su propia naturaleza bumana racional, conocer la naturaleza de otras criaturas, conocer sus propias tendencias y aptitudes, y con todo esto el intelecto práctico humano fructifica natural y necesariamente un juicio práctico o precepto de la ley natural, que implica un perfeccionarse. Esto sucede porque los entes humanos o personas poseen intrínsecamente un acto de ser, una naturaleza humana, y unas operaciones en busca de su propio bien, perfección o fin, y unas operaciones para tras-

\footnotetext{
56 S. Th., I-II, q. 94, a. 1, ad 2.

${ }^{57}$ Cfr., PALACIOS, E, Filosofia del saber, Encuentro, Madrid, 2012, pp. 384-385.

${ }^{58}$ Cfr., Metafísica tomista, op. cit., p. 425.

${ }^{59}$ Cfr., The Treatise on Law, op. cit., p. 236.
}

Claridades. Revista de filosofía 8 (2016) 
mitir, comunicar su propia perfección o actualidad, según la ley natural. Es importante resaltar que los únicos entes que exigen una finalidad libremente son los seres racionales, y de esto fructifica natural y libremente en el hombre una serie de libertades y responsabilidades. Sui generis, un perro, un gato o un canario irracional, también buscan realizar su naturaleza, pero solo según la ley eterna. Libertad y responsabilidad en el ser racional van sustancialmente unidas porque el hombre es naturalmente, por su voluntad, autodeterminante y árbitro de sus propias acciones y por tanto no solo libre, con sus derechos, sino que también responsable de sus acciones. ${ }^{60}$

El bien moral radicalmente se encuentra de forma incoada ya en el acto de ser de la persona dado que se trata de un ente imperecedero, pues aunque la esencia o naturaleza de este ente sea compuesta de materia y forma, su forma es tal que no es simplemente forma sustancial de un cuerpo material (quod), sino que es al mismo tiempo espiritual, ya que puede actuar aún separada de la materia (quo) y por tanto, es universalmente abierta al bien ontológico.

El principio de la operación intelectual, llamado alma humana, es incorpóreo y subsistente. Es evidente que el hombre por el entendimiento puede conocer las naturalezas de todos los cuerpos. Para conocer una clase de cosas es necesario que en la propia naturaleza no esté contenida ninguna de esas cosas que se va a conocer (...). Así, pues, si el principio intelectual contuviera la naturaleza de algo corpóreo, no podría conocer todos los cuerpos. Todo cuerpo tiene una naturaleza determinada. Así, pues, es imposible que el principio intelectual sea cuerpo (...). Hay que concluir, por tanto, que el alma humana, llamada entendimiento o mente, es algo incorpóreo y subsistente. ${ }^{61}$

En este sentido el bien moral formalmente se refiere a las operaciones libres y humanas, según su fin último que debe naturalmente buscar "Busca y persigue el bien y evita el mal." "' Se debe observar que el bien físico, que es el bien que buscan los agentes físicos (naturales, en el sentido de irracionales), es mucho menor que el que buscan los agentes libres. Porque aunque el bien está incoadamente en el (acto de) ser y esencia o naturaleza de estos seres irracionales -compuesta de materia y for-

${ }^{60}$ Cfr., Metafísica tomista, op. cit., pp. 143-144.

${ }^{61}$ S. Th., I, q. 75, a. 2, co.

62 S. Th., I-II, q. 94, a. 2, co.

Claridades. Revista de filosofía 8 (2016) 
ma sustancial material no espiritual- se refiere a sus operaciones que son muy reducidas con lo que estos seres no son capaces de conocer ni aprehender intelectualmente la noción de fin último. ${ }^{63}$

\section{CONCLUSIÓN}

Se puede concluir señalando que la ética humana de Aquino es una consecuencia natural de su ontología, particularmente los conceptos de ser (ente) y bien de la persona. Cuando se trata de ley moral natural en el hombre, según Santo Tomás, el único sentido lícito y utilizable del concepto naturaleza bumana es el metafísico, teleológico, libre y responsable propio del hombre en cuanto tal. La ley moral natural del angélico es esencialmente metafísica como el concepto de naturaleza humana.

Si la naturaleza se concibe solo en sentido material, como naturaleza biológica o física, se debe decir que el hombre en cuanto tal, con su naturaleza específica y genuinamente racional, no posee una naturaleza, ya que sobre todo es un ser racional y libre, que puede ser todas las cosas por su intelecto. ${ }^{64}$

Sin embargo, si la naturaleza se concibe en sentido metafísico, como principio de las operaciones, todo ente posee una naturaleza o esencia, que especifica su modo genuino de ser y actuar. En este sentido el hombre sí tiene una naturaleza humana, esto es, una naturaleza libre y racional. ${ }^{65}$ Es más, una persona que no haya alcanzado nunca el uso de razón, no por ello debe ser considerada menos persona, puesto que posee en esta vida, por naturaleza, una inteligencia y voluntad abiertas al absoluto. ${ }^{66}$

Además, las inclinaciones de la naturaleza humana están jerarquizadas entre sí, pues las que distinguen al hombre de las demás especies -las específicamente humanas- son las más importantes. ${ }^{67}$ Hay en el hombre una inclinación al bien correspondiente a la naturaleza racional, que es la suya propia, como es, por ejemplo, la inclinación natural a buscar la verdad acerca de Dios y a vivir en sociedad. ${ }^{68}$ Por tanto, la persona, que es el

${ }^{63}$ Cfr., Metafísica tomista, op. cit, pp. 141-142.

${ }^{64}$ Cfr., Contra Gentiles, lib. 3, cap. 112.

${ }^{65}$ Cfr., LUCAS LUCAS, R., Veritaris Splendor, San Paolo, Milano, 1994, p. 278

${ }^{66}$ Cfr., LUCAS LUCAS, R., L'uomo. Spiritu incarnato, San Paolo, Milano, 2007, pp. $277-$ 278.

${ }^{67}$ Cfr., Proposicoes acerca do conceito do naturaleza... op. cit., p. 16.

${ }^{68}$ Cfr., S. Th., I-II, q. 94, a.2, co. 
ente más perfecto de toda la realidad, ${ }^{69}$ se automueve por su naturaleza racional a buscar su bien y fin racional o perfección moral. "Busca el bien (universal y particular-humano) y evita el mal (universal y particularhumano)."

Bibliografía.

ALARCON, E. (2000) Corpus Thomisticum. [en linea]. http://www.corpusthomisticum.org/ [Consulta: 10/11/2015].

BROCK, S. L. (1988). The legal character of natural law according to St Thomas Aquinas, Toronto, University of Toronto.

COTTIER, G. M. (2010). Proposições acerca do conceito de natureza humana sobre o direito natural. Aquinate, 12, 12-16.

DEWAN, L. (1990). St. Thomas, our natural lights, and the moral order. Angelicum, 67, 283-307

FIORENTINO, F. (2005). In De Veritate, Milano: Bompiani

GARCÍA, J. (2001). Metafísica tomista. Ontología, gnoseología y teología natural, Pamplona: Eunsa.

HENLE, R. (1993). The Treatise on Law, Indiana: University of Notre Dame press.

LUCAS LUCAS, R. (2007). L'uomo. Spiritu incarnato, Torino: San Paolo. - (1994), Veritatis Splendor, Milano: San Paolo.

OSUNA, A. (1989). Tratado de la ley en general. In Suma de Teología. Parte I-II, Madrid: BAC.

PALACIOS, E. (2012). Filosofía del saber, Madrid: Encuentro.

ROYO, A. (2012). Teología moral para seglares, vol. I, Madrid: BAC.

SELLÉS, J. F. (1991). Razón teórica y razón práctica según Tomás de Aquino. Anuario Filosófico, 101,1-87.

SORIA, C. (1956). Tratado de la ley en general. In Suma de Teología. Parte I-II, Madrid: BAC.

ABBOT, A., Neuroscience: The brain, interrupted, http://www.nature.com/news/neuroscience-the-brain-interrupted-

1.16831. [Consulta: 13/11/2015].

VV. AA, http://www.urbanchildinstitute.org/why-0-3/baby-and-brain. [Consulta: 10/11/2015].

${ }^{69}$ Cfr., S. Th., I, q. 29, a. 3, co.

${ }^{70}$ S. Th., I-II, q. 94, a.2, co.

Claridades. Revista de filosofía 8 (2016) 
Augusto Trujillo Werner es doctorando en la Universidad de Málaga

Lineas de investigación:

Metafísica y filosofía moral.

Publicaciones recientes:

- "Ens, verum, bonum, universales en Tomás de Aquino", Revista de filosofía de la Universidad de Costa Rica (RFUCR), 144/66 (2017), pp. 61-69.

Dirección electrónica: augustotrujillowerner@gmail.com 